\title{
Advances in the Diagnosis of Human Strongyloidiasis
}

\author{
Ana Requena-Mendez • Dora Buonfrate - Zeno Bisoffi • \\ Jose Muñoz Gutiérrez
}

Published online: 14 October 2014

(C) Springer International Publishing AG 2014

\begin{abstract}
Strongyloidiasis is an intestinal parasitic infection that is particularly relevant in immunosuppressed patients because it can cause severe disseminated disease. This review discusses the recent advances in the diagnosis of strongyloidiasis. We suggest clinical and epidemiologic criteria for the diagnosis and screening of strongyloidiasis, taking into account different epidemiologic contexts. The state of the art of the diagnosis of strongyloidiasis is discussed including parasitologic methods that are commonly used despite having low sensitivity; serology, which has demonstrated better sensitivity (with some exceptions such as travelers or immunosuppressed patients), and molecular biology methods, which have virtually $100 \%$ specificity. Finally, we discuss different strategies to follow up patients after treatment, highlighting the importance of having accurate and reliable follow-up markers when assessing treatment efficacy both in a clinical and research context.
\end{abstract}

Keywords Strongyloides · Strongyloidiasis $\cdot$ Helminth · Diagnosis · Serology · ELISA · IFAT · Agar plate culture ·

\footnotetext{
A. Requena-Mendez $\cdot$ J. M. Gutiérrez $(\triangle)$

Barcelona Centre for International Health Research (CRESIB), Hospital Clínic-Universitat de Barcelona, C/ Roselló 132 4,

Barcelona 08036, Spain

e-mail: jose.munoz@cresib.cat

A. Requena-Mendez

e-mail: ana.requena@cresib.cat

D. Buonfrate $\cdot$ Z. Bisoffi

Centre for Tropical Diseases (CTD), Sacro Cuore Hospital, Via

Sempreboni, Negrar, 37024 Verona, Italy

D. Buonfrate

e-mail: dora.buonfrate@sacrocuore.it

Z. Bisoffi

e-mail: zeno.bisoffi@sacrocuore.it
}

Baermann method · Marker · PCR · Stool examination · Review follow-up

\section{Introduction}

Strongyloides stercoralis is a unique nematode that is acquired by humans when larvae penetrate intact skin following contact with infected soil $[1,2 \cdot]$. After a complex cycle, the female adult becomes established in the small intestine, where it lays eggs on a daily basis. Strongyloides eggs usually hatch in the intestine, and are therefore only exceptionally found in the feces. The presence of first-stage larvae in feces is diagnostic for strongyloidiasis. Most larvae develop into third-stage (infective) larvae while still in the intestine, where they are able to penetrate the bowel wall and initiate a new cycle [1]. This unique autoinfection cycle means that infected individuals will remain infected for a lifetime if not appropriately treated [2•] (Fig. 1).

In immunosuppressive conditions, autoinfection may predominate and become overwhelming, with parasites at different stages of development invading virtually every host organ and tissue [3]. The result is the development of hyperinfection or disseminated strongyloidiasis. The first is defined as the infection confined to the lungs and gastrointestinal tract but with signs or symptoms of severe disease in relation to an elevated number of larvae, whereas the latter, which is the most severe form of hyperinfection, larvae might be found in any organ, other than the respiratory or gastrointestinal tract [4••]. Disseminated strongyloidiasis is fatal in over $50 \%$ of cases, and is particularly common in patients on immunosuppressive treatment $[4 \bullet \bullet, 5]$. According to a recent systematic review, relatively few cases of dissemination have been reported [4••], but we believe that these cases are only the tip of the iceberg, as apparent causes of death such as Gram-negative sepsis, pneumonia, and/or meningitis are not usually associated with a parasitic origin in clinicians' minds. Consequently, it is crucial 
Fig. 1 Life cycle of Strongyloides stercoralis

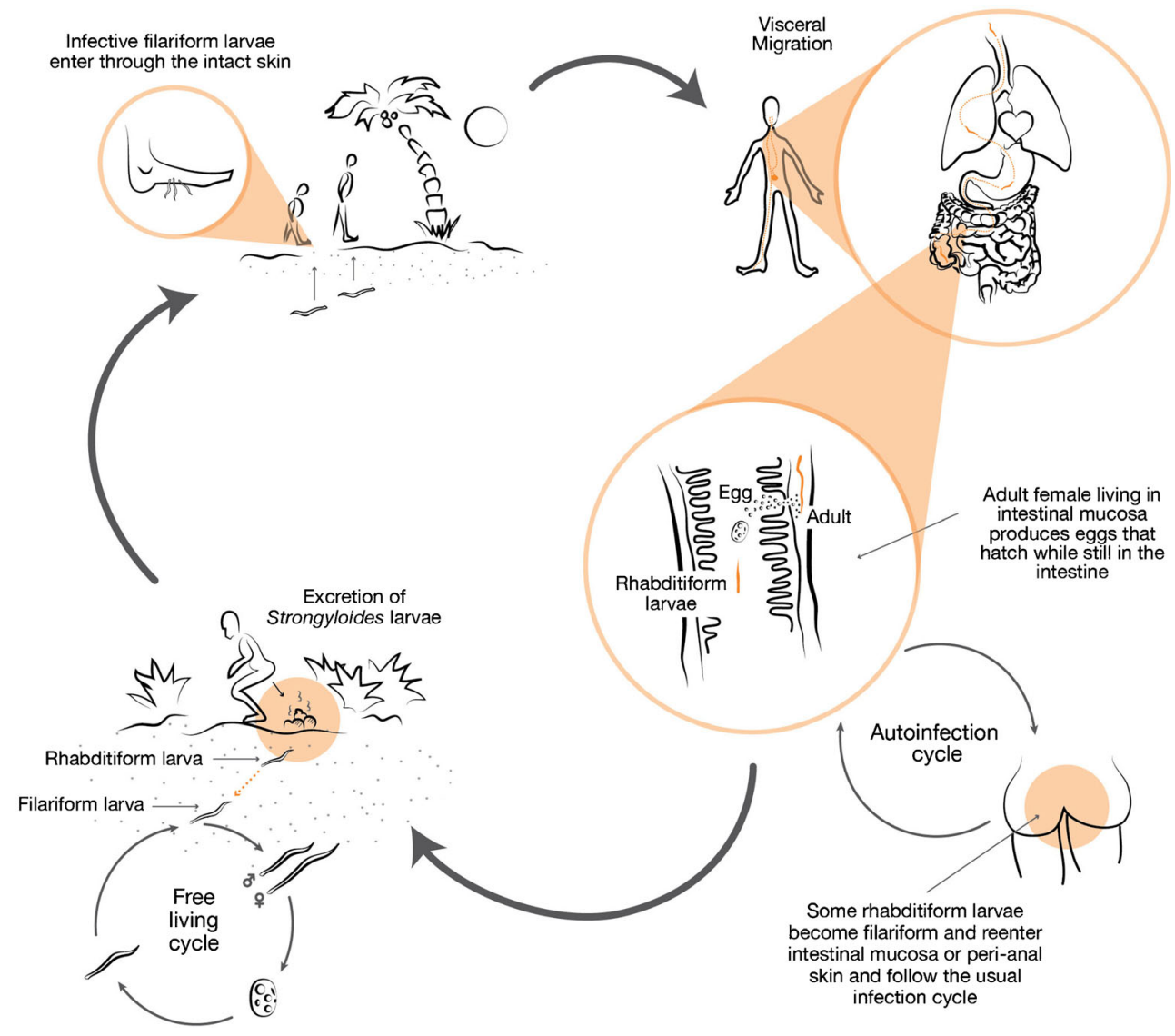

to detect and effectively treat infection as early as possible, because chronic strongyloidiasis can be fatal and indeed has been defined by some authors as a "time bomb" [6].

The global burden of strongyloidiasis has long been underestimated, mostly because of a lack of sensitivity of commonly used, fecal-based diagnostic methods [7••, 8, 9]. The traditional figure of 30-100 million infected people worldwide was recently questioned [10], and a new figure of over 350 million proposed [10,11]. Diagnosis of strongyloidiasis is often delayed or overlooked because the infection is frequently asymptomatic or associated with non-specific gastrointestinal symptoms. Appropriate diagnostic methods are therefore crucial to improve our knowledge of the epidemiology of strongyloidiasis and ensure its inclusion in studies of soil-transmitted helminth (STH) infections. Moreover, improved diagnostics are essential for effective screening of immunosuppressed patients in populations at risk.

In this review, we discuss recent advances in diagnostic tests for strongyloidiasis.

\section{Who should be Tested for Strongyloidiasis?}

Community-based clinicians must be aware of the risks of strongyloidiasis and be able to clearly identify individuals who should be tested. The guiding criteria will vary according to whether the context is clinical (diagnosis) or population based (screening).

An individual diagnosis of strongyloidiasis should be suspected even in asymptomatic individuals, but clinical suspicion can be raised by some clinical findings. With the exception of larva currens, which is virtually pathognomonic for strongyloidiasis, albeit very uncommon, signs and symptoms of chronic strongyloidiasis are usually scarce and non-specific [2•]. In highly endemic countries, S. stercoralis infection should be considered in any patient presenting with abdominal discomfort, and/or itching or skin rash [12]. Wheezing, dry cough, and related respiratory problems are also quite common [13]. Peripheral eosinophilia can support the suspicion of strongyloidiasis. Nonetheless, while eosinophilia has shown a high positive predictive value in some settings [14], in others, it has been found to be a poor predictor of infection [15]. In non-endemic countries, the above clinical criteria should be combined with consideration of the risk of exposure in the case of immigrants or travelers, regardless of the potential incubation period. In some regions of formerly endemic countries, such as Italy and Spain, individuals, and older individuals in particular, may harbor infections following exposure several decades 
earlier [14]. An eosinophil count of over 500 cells $/ \mu \mathrm{L}$ should be sufficient to raise suspicion.

Strongyloidiasis should be urgently ruled out in patients with clinical manifestations of hyperinfection syndrome or disseminated disease. In such cases, stool examination methods are highly sensitive owing to the massive parasite burden and, in severe cases, larvae can be found in other fluids such as sputum or cerebrospinal fluid $[5,7 \cdot \bullet]$.

The criteria for population-based screening of S. stercoralis infection in people at risk are still under discussion. In our view, all individuals who are, or are likely to become immunosuppressed (e.g., HIV- or HTLV1-infected individuals, oncologic patients, solid or bone marrow transplant recipients, candidates for corticosteroid or immunosuppressive therapy, including anti-tumor necrosis factor therapy), and who may have been exposed to the infection, should be screened and appropriately treated if necessary. The recommended method for screening is serology, if available. Presumptive treatment might be a more cost-effective alternative, but evidence is still lacking $[16 \bullet]$.

There is no evidence to support routine screening of strongyloidiasis in immunocompetent patients. Even though eosinophilia has not been found to have a high positive predictive value for parasitic infections [17], a reasonable strategy could be to perform a complete blood work-up in high-risk individuals and screening tests in patients with a raised eosinophil count.

A summary of our recommendations for the diagnosis and screening of strongyloidiasis is given in Table 1 .

\section{How to Diagnose Strongyloidiasis (see Table 2)}

\author{
Parasitologic Methods
}

Diagnosis of strongyloidiasis has traditionally been based on parasitologic methods aimed at detecting $S$. stercoralis larvae in feces rather than ova, in contrast to other intestinal helminths $[7 \bullet \bullet]$. However, as already mentioned, the sensitivity of most of these methods is very low [18] because of intermittent larval excretion $[19,20]$. While simple and inexpensive, a direct fecal smear examination (DS) detects less than $30 \%$ of chronic infections [7 $\left.\bullet^{\bullet}\right]$. The Kato-Katz method is a simple variation of the DS based on a microscopic examination aimed at measuring the intensity of infection by counting the number of eggs per gram [21]. It has been widely used in field studies of helminth infections [22, 23] because it quantifies the intensity of infection and is therefore very useful in public health interventions aimed at reducing the burden of STH infections [24]. However, it fails to detect low-density infections and, more importantly, it is not useful for detecting $S$. stercoralis [22]. The use of inadequate techniques for detecting $S$. stercoralis infections has largely contributed to the underestimation of the burden of strongyloidiasis in research studies.

Other methods, such as fecal concentration techniques, have been proposed to improve the sensitivity of the parasitologic diagnosis of strongyloidiasis. The formalin-ether concentration technique (FECT), described by Ritchie, is currently the most widely used test in clinical practice, although it also lacks sufficient sensitivity [19, 25, 26], particularly in

Table 1 Recommendations for screening and diagnosis of Strongyloides stercoralis infection in endemic and non-endemic areas

\begin{tabular}{|c|c|c|}
\hline & Endemic areas & Non-endemic areas \\
\hline Screening & $\begin{array}{l}\text { Immunosuppressed individuals or candidates for immunosuppressive } \\
\text { therapy }\end{array}$ & $\begin{array}{l}\text { - Immunosuppressed individuals or candidates for } \\
\text { immunosuppressive therapy } \\
\text { Blood tests for migrants or individuals with a relevant travel history } \\
\text { and specific testing for } S \text {. stercoralis infection in those with } \\
\text { eosinophilia }\end{array}$ \\
\hline Diagnosis & $\begin{array}{l}\text { Strongyloidiasis should be considered: } \\
\text { - in immunocompetent individuals with: } \\
\text { - Abdominal discomfort } \\
\text { - Itching or skin rash } \\
\text { - Respiratory problems (wheezing, dry cough) } \\
\text { - Unexplained eosinophilia } \\
\text { in the presence of signs or symptoms of disseminated disease, i.e., } \\
\text { worsening abdominal problems (abdominal pain, heavy diarrhea, } \\
\text { ileus, obstruction, bleeding); severe and worsening pneumonitis } \\
\text { and respiratory failure; sepsis; meningitis; febrile coma } \\
\text { (eosinophilia is usually lacking) }\end{array}$ & $\begin{array}{l}\text { Strongyloidiasis should be considered } \\
\text { - in immunocompetent individuals with: } \\
\text { - Abdominal discomfort } \\
\text { - Itching or skin rash } \\
\text { - Respiratory problems (wheezing, dry cough) } \\
\text { - Unexplained eosinophilia } \\
\text { PLUS } \\
\text { - Relevant history of exposure to strongyloidiasis (travelers, migrants } \\
\text { from endemic areas) } \\
\text { OR } \\
\text { - Older people from formerly endemic areas (e.g., Spain and Italy) } \\
\text { in the presence of signs or symptoms of disseminated disease, i.e., } \\
\quad \text { worsening abdominal problems (abdominal pain, heavy diarrhea, } \\
\text { ileus, obstruction, bleeding); severe and worsening pneumonitis } \\
\text { and respiratory failure; sepsis; meningitis; febrile coma } \\
\text { (eosinophilia usually lacking) }\end{array}$ \\
\hline
\end{tabular}




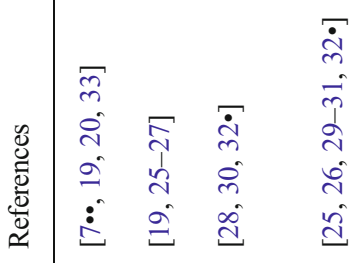

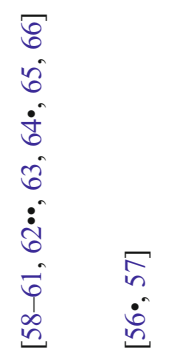

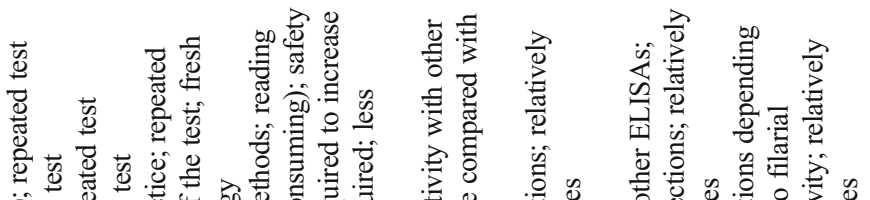

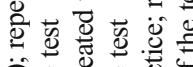

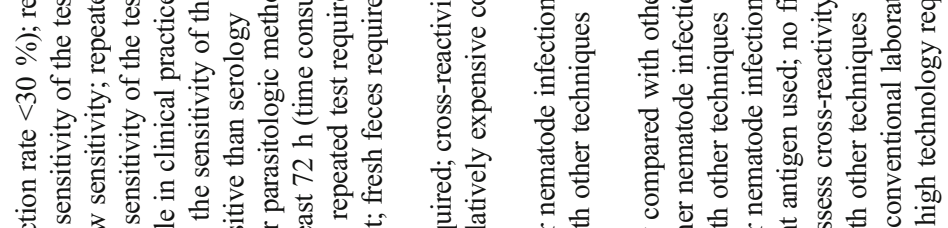

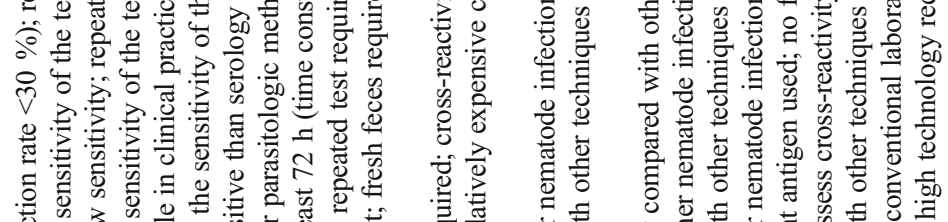

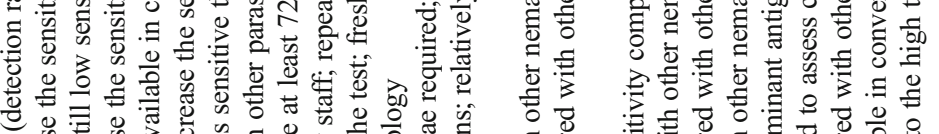

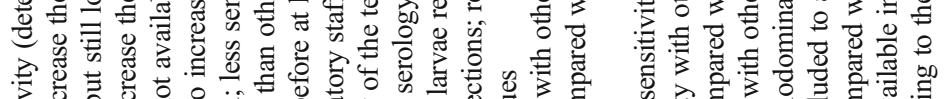

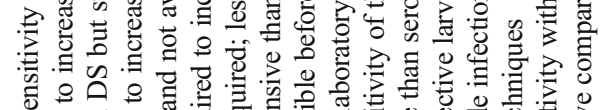

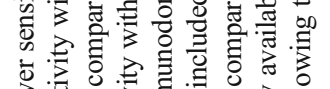

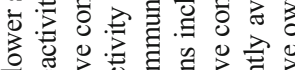

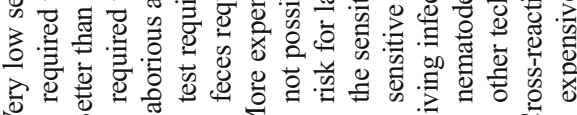

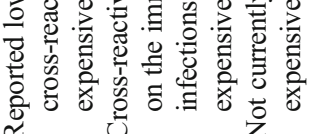

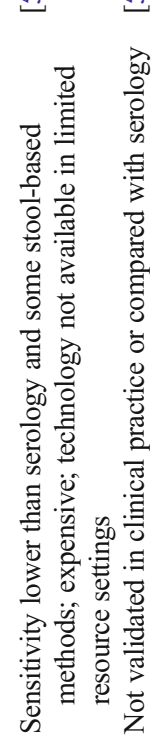

计
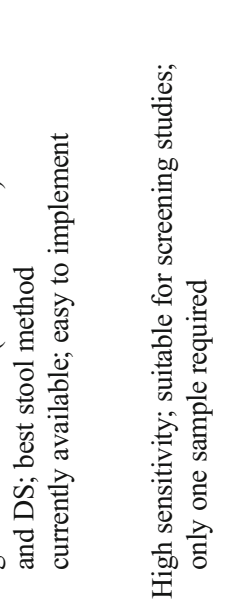

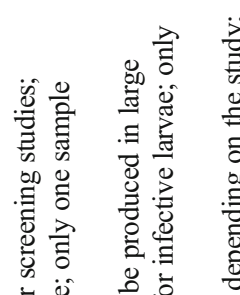

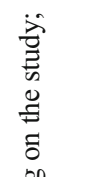
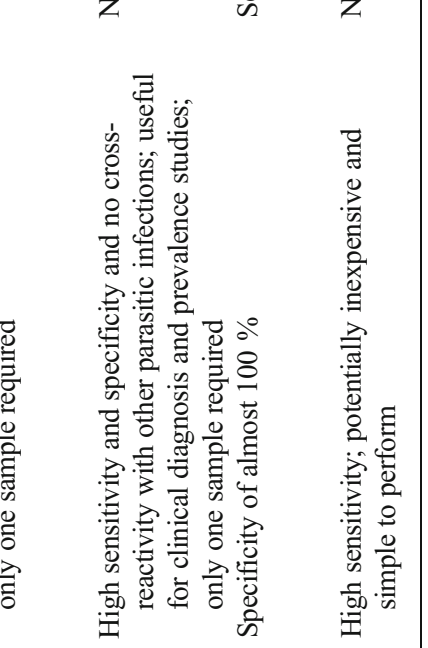

总

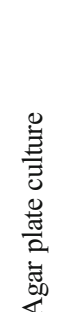

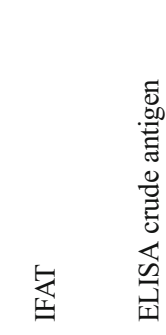

蒙

鱼

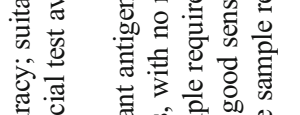

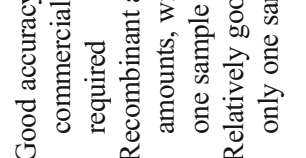

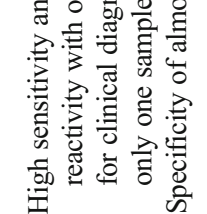

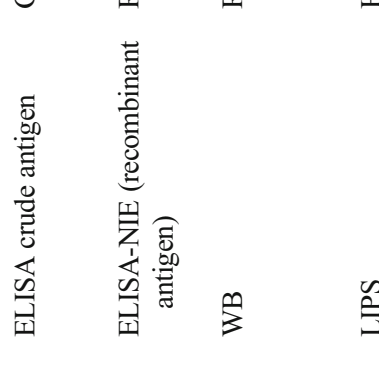

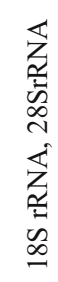

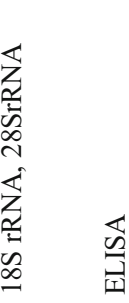

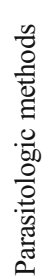

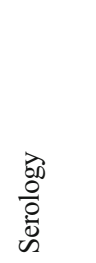

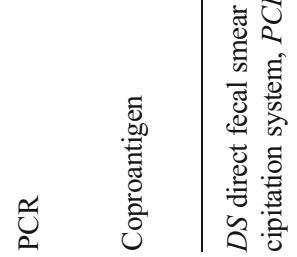


low-density infections [27]. Other more elaborate methods have been employed in recent years, including the Baermann method, which is based on the water tropism of S. stercoralis larvae [28], and agar plate culture (APC) [29]. Both methods have been shown to be superior to FECT and DS, with a 1.6to 6-fold increase in detection rates [25, 26, 28-31, 32•]. Yet again, however, owing to low parasite loads and intermittent larval excretion, they have a high number of false negatives in chronic infections. Moreover, they are very laborious and require the presence of living larvae, making them logistically more complicated to use in clinical settings [7••]. The diagnostic sensitivity of APC and other parasitologic techniques can be increased through repeated stool examination [22, 23, $33,34]$.

\section{Serology}

Immunologic methods have demonstrated better sensitivity than the parasitologic techniques discussed above. Most methods, however, have the drawback of cross-reactivity with other nematode infections, particularly filarial infections [35-37]. This is particularly important when evaluating results in endemic areas or in immigrants from areas with a high density of helminths. Immunologic methods thus hold promise as screening tools and for use in individual diagnoses where the possibility of co-infection is low [7••]. Serology has been found to be less sensitive in travelers returning from endemic countries than immigrants from these countries (73\% vs $98 \%$ ) [38]. One possible explanation is the shorter exposure time to the parasite in the former. Serology also seems to be less sensitive in immunosuppressed patients, possibly because of a reduced antibody response, although evidence in this regard is limited [39-41].

Several serum antibody tests have been tested over many years. Three tests in particular have shown high sensitivity and specificity: the immunofluorescence antibody test (IFAT), the enzyme-linked immunoabsorbent assay (ELISA), and immunoblotting [7••, 42-47]. ELISA is considered the easiest test, and is the most widely used technique for the diagnosis of strongyloidiasis, with sensitivity rates of between $73 \%$ and $100 \%$ [7••]. Several in-house ELISAs have been designed from crude antigenic extracts of filariform larvae, some of them from S. stercoralis [46-48] and others from $S$. venezuelensis or $S$. ratti [49-51]. In addition, two commercial kits are currently available: Bordier-ELISA from $S$. ratti antigen (Bordier Affinity products) and IVD-ELISA from S. stercoralis antigen (S-stercoralis serology Microwell ELISA Kit; IVD Research, Carlsbad, CA, USA) [45]. More recently, a recombinant antigen, NIE, [52], which has the advantage of being produced in large amounts, has also shown promising results in the NIE-ELISA test and the luciferase immunoprecipitation system (LIPS) in particular, as no crossreactivity with other parasitic infections was found [53, 54].
A recent study compared five serologic tests (IFAT, IVDELISA, Bordier-ELISA, NIE-ELISA, NIE-LIPS) for the diagnosis of $S$. stercoralis infection [6, 55••]. Although the study had a retrospective design and used anonymized serum samples, the authors interestingly used a composite reference standard to establish the diagnosis of strongyloidiasis in addition to the classic gold standard based on a single parasitologic method. This approach allowed a more realistic classification of cases and controls. IVD-ELISA showed the highest concordance with the reference standard (Cohen's Kappa 0.9, confidence interval $0.86-0.95)$. IFAT was the most sensitive test (94.6\% confidence interval 91.2-96.9) followed by the commercial IVD-ELISA test. These tests, therefore, could be considered suitable for screening high-risk populations. The most specific, and accurate, test was NIE-LIPS, making it ideal for use in clinical trials. It is, however, only currently available for research purposes. Based on the findings of this comparative study, the two commercial tests appeared to work quite well in clinical practice and thus might be useful for screening and diagnosis in populations at risk. In the case of individual diagnoses, a higher optical density (OD) cut-off could be used to increase test specificity, particularly for immigrants from areas with a high incidence of other helminth infections.

ELISA tests have also been used to detect $S$. stercoralis coproantigen in fecal samples. Although results in human samples are limited [36], the method has proven to be very effective in detecting coproantigen in the feces of patients with $S$. stercoralis infection. Furthermore, no cross-reactivity with other parasitic infections was observed. However, it needs to be clinically validated before it can be used in routine practice.

\section{Molecular Biology}

Molecular polymerase chain reaction (PCR) techniques specifically developed for the diagnosis of strongyloidiasis have generally achieved $100 \%$ specificity in several studies based on both simple and nested PCR [58-60]. The sensitivity reported to date was not superior to that of other parasitologic methods, in part probably because PCR inhibitors are commonly found in fecal samples and also possibly because the fecal samples used were very small.

Real-time PCR techniques targeting 18S rRNA and 28S rRNA have also demonstrated high analytic sensitivity and specificity [61, 62••, 63]. Whilst real-time PCR has shown very high specificity in human samples, it again has limited sensitivity, and has not proven to be diagnostically superior to other parasitologic techniques such as the Baermann method or APC $[61,63,64 \bullet]$, particularly in low-density infections, supporting previous findings from animal models $[65,66]$. However, recent improvements of this technique may increase the sensitivity in the near future. 
Another important drawback of PCR techniques is that they are laborious and expensive, and are therefore not readily available outside research facilities.

The loop-mediated isothermal amplification (LAMP) assay is a molecular technique that performs highly specific and sensitive amplifications of nucleic acid to detect pathogens [67]. It has been used in the diagnosis of several parasitic infections, including malaria, leishmaniasis, and cysticercosis [68-70]. It has several advantages: it uses stable reagents, is simple to use, and does not require a complex infrastructure. Accordingly, it has already been used in low-resource settings $[71,72]$. The LAMP assay has also been evaluated in preliminary studies for the detection of $S$. stercoralis, with very promising results [73•]. However, before it can be introduced on a widespread scale, it needs to be clinically validated and also requires more simplified or miniaturized extraction methods to facilitate use in remote areas [73•].

\section{How to Follow Patients after Treatment}

Accurate reliable methods for monitoring individuals with strongyloidiasis after treatment are of great importance for two main reasons. First, in clinical practice, the goal of treatment is to cure infection and prevent severe disseminated disease, which is a risk even in patients with low parasite burdens. Microbiologic tests should therefore be requested after treatment to detect treatment failure. Second, in the context of clinical research, follow-up markers are needed to assess the effectiveness of new anti-helminthic drugs and combinations of existing treatments.

Examination of a single stool sample using parasitologic methods is not sensitive enough to detect treatment failure and is not currently recommended in clinical practice [74]. Some authors have suggested analyzing stool samples collected on 2 consecutive days with the quantitative Baermann test. This has proven to be highly sensitive ( $>90 \%$ ) for post-treatment follow-up, but the lack of a reliable gold standard for comparison makes results difficult to interpret [75]. APC has been shown to be far more sensitive than standard DS, but the method produces similar results to those observed with the Baermann test and does not meet optimal follow-up criteria (Table 1) [7••, 20].

Serologic testing, if available, could be a suitable alternative for assessing cure, but only some ELISA and IFAT tests have been evaluated for this purpose. Whilst seroconversion does not always take place in patients with strongyloidiasis, serum levels tend to decrease after effective treatment $[9,47$, 76-81].

Kobayashi et al. [9] observed that extremely high pretreatment OD levels in ELISA tended to remain positive at followup. It is possible that levels take longer to fall below the cut-off for positivity in patients who have been infected for many years [83]. A post-treatment OD value of over 0.6 has been proposed for defining response to treatment. In the study by Kobayashi et al., $20 \%$ of patients in whom OD values decreased inadequately and who were evaluated again with stool tests showed positive results. This suggests that persistence of positive serology in the absence of a consistent fall in OD might be indicative of treatment failure [9, 78]. This criterion is now used by most authors assessing serologic response to treatment [7••]. Biggs et al. [80] followed patients treated with two doses of ivermectin for 24 months, and found a significant cure rate (65\%) according to Kobayashi's criterion. Moreover, antibody titers decreased to some extent in $95 \%$ of individuals.

LIPS and IFAT assays have also been evaluated for their ability to confirm a cure for $S$. stercoralis infection. While antibody titers tend to decrease after treatment, a reliable cutoff value for cure is lacking. Serologic follow-up for 1 year has been recommended to ensure a sustained decrease in serologic titers [80].

Finally, several authors who have investigated the value of eosinophil count as a marker of cure have reported a significant reduction in mean values after treatment [47, 78-81]. The fluctuating nature of eosinophil counts in helminth infections, however, poses a challenge. Moreover, although a normal eosinophil count following treatment does not confirm treatment response, persistent eosinophilia has been observed in non-responders [78].

When evaluating results in S. stercoralis-endemic countries, re-infection should be taken into account, because it can contribute to persistent serologic titers in a fraction of patients [82].

Assessment of treatment efficacy is heavily dependent on the method used to follow patients. Fecal-based methods (DS, formol-ether concentration, and stool culture) tend to overestimate treatment efficacy compared with serologic methods. One clinical trial comparing the efficacy of ivermectin and thiabendazole for treating strongyloidiasis [83], for instance, reported cure rates of $56.6 \%$ for ivermectin and $52.2 \%$ for thiabendazole based on serologic testing (in-house IFAT) but rates of $85.7 \%$ and $94.6 \%$, respectively, for direct stool testing.

We support continued research into the value of new diagnostic and follow-up tools for strongyloidiasis, and currently recommend using a combination of both serology 6-12 months after treatment and stool methods (preferably Baermann and/or Koga agar culture) for the evaluation of a cure in patients with strongyloidiasis.

\section{Conclusions}

Strongyloides stercoralis has been the neglected member of the STH family for decades, mostly because of a lack of 
diagnostic accuracy and difficulties in evaluating public health interventions. The global prevalence and clinical impact of strongyloidiasis are likely to be greatly underestimated. Furthermore, screening criteria are not well defined, and strongyloidiasis has largely been neglected by researchers evaluating treatment response in patients with STH infections in public health interventions.

Parasitologic methods based on stool examination, in particular the commonly used Kato-Katz method, lack sensitivity for diagnosis and follow-up. Several antibody tests have shown good sensitivity and specificity, but are still not ideal, and the usefulness of molecular biology methods remains to be tested.

In recent years, there has been a renewed interest in the study of strongyloidiasis, and several scientific groups and research institutions are advocating raising the profile of strongyloidiasis and giving it the attention it merits. Strongyloides stercoralis infection is slowly being contemplated in some studies on STH infections, and trials are underway to evaluate the most efficacious treatment regimen for eliminating infection. It is therefore extremely important to have an accurate case definition for strongyloidiasis based on robust diagnostic techniques and reliable follow-up.

In the absence of a reliable gold standard, recent research studies have used composite reference standards to provide a more accurate case definition and evaluate the sensitivity and specificity of serologic methods for the diagnosis of strongyloidiasis and evaluation of treatment response. High serologic cut-off values have been used in clinical trials to achieve a more specific case definition, but very possibly at the expense of sensitivity. In clinical practice, diagnosis of strongyloidiasis should be based on a combination of repeated parasitologic exams and serology (with a standard cut-off), if available.

Improving the diagnostic yield of easily implementable tests is crucial for overcoming the epidemiologic and therapeutic challenges posed by $S$. stercoralis infection worldwide. We envisage a short-term future in which strongyloidiasis will be taken into account in immunosuppressed patients at risk worldwide and included in preventive chemotherapy strategies for the control of STH infection.

Acknowledgments The CRESIB Research Group receives funds from AGAUR (project 2009SGR385) and also from the project RICET (RD12/0018/0010) within the Spanish National Plan of R+D + and cofunded by ISCIII-Subdireccion General de Evaluacion and the Fondo Europeo de Desarrollo Regional (FEDER).

\section{Compliance with Ethics Guidelines}

Conflict of Interest Ana Requena-Mendez, Dora Buonfrate, Zeno Bisoffi, and Jose Muñoz declare that they have no conflict of interest.

Human and Animal Rights and Informed Consent This article does not contain any studies with human or animal subjects performed by any of the authors.

\section{References}

Papers of particular interest, published recently, have been highlighted as:

- Of importance

•- Of major importance

1. Bethony J, Brooker S, Albonico M, Geiger SM, Loukas A, Diemert $\mathrm{D}$, et al. Soil-transmitted helminth infections: ascariasis, trichuriasis, and hookworm. Lancet. 2006;367(9521):1521-32.

2. Greaves D, Coggle S, Pollard C, Aliyu SH, Moore EM. Strongyloides stercoralis infection. BMJ. 2013;347:f4610. General review of the $S$. stercoralis infection.

3. Keiser PB, Nutman TB. Strongyloides stercoralis in the immunocompromised population. Clin Microbiol Rev. 2004;17(1):208-17.

4.• Buonfrate D, Requena-Mendez A, Angheben A, Munoz J, Gobbi F, Van Den Ende J, et al. Severe strongyloidiasis: a systematic review of case reports. BMC Infect Dis. 2013;13:78. This systematic review reports all cases of hyperinfection and disseminated strongyloidiasis published in the literature and discusses the main risk factors associated with severe disease.

5. Marcos LA, Terashima A, Canales M, Gotuzzo E. Update on strongyloidiasis in the immunocompromised host. Curr Infect Dis Rep. 2011;13(1):35-46.

6. Caumes E, Keystone JS. Acute strongyloidiasis: a rarity. Chronic strongyloidiasis: a time bomb! J Travel Med. 2011;18(2):71-2.

7.• Requena-Mendez A, Chiodini P, Bisoffi Z, Buonfrate D, Gotuzzo E, Munoz J. The laboratory diagnosis and follow up of strongyloidiasis: a systematic review. PLoS Negl Trop Dis. 2013;7(1):e2002. This recent systematic review updates all diagnostic methods for strongyloidiasis and discusses the advantage and disadvantages of each one.

8. Boscolo M, Gobbo M, Mantovani W, Degani M, Anselmi M, Monteiro GB, et al. Evaluation of an indirect immunofluorescence assay for strongyloidiasis as a tool for diagnosis and follow-up. Clin Vaccine Immunol. 2007;14(2):129-33.

9. Kobayashi J, Sato Y, Toma H, Takara M, Shiroma Y. Application of enzyme immunoassay for postchemotherapy evaluation of human strongyloidiasis. Diagn Microbiol Infect Dis. 1994;18(1):19-23.

10. Bisoffi Z, Buonfrate D, Montresor A, Requena-Mendez A, Munoz J, Krolewiecki AJ, et al. Strongyloides stercoralis: a plea for action. PLoS Negl Trop Dis. 2013;7(5):e2214.

11. Schar F, Trostdorf U, Giardina F, Khieu V, Muth S, Marti H, et al. Strongyloides stercoralis: global distribution and risk factors. PLoS Negl Trop Dis. 2013;7(7):e2288.

12. Khieu V, Srey S, Schar F, Muth S, Marti H, Odermatt P. Strongyloides stercoralis is a cause of abdominal pain, diarrhea and urticaria in rural Cambodia. BMC Res Notes. 2013;6:200.

13. Montes M, Sawhney C, Barros N. Strongyloides stercoralis: there but not seen. Curr Opin Infect Dis. 2010;23(5):500-4.

14. Abrescia FF, Falda A, Caramaschi G, Scalzini A, Gobbi F, Angheben A, et al. Reemergence of strongyloidiasis, northern Italy. Emerg Infect Dis. 2009;15(9):1531-3.

15. Naidu P, Yanow SK, Kowalewska-Grochowska KT. Eosinophilia: a poor predictor of Strongyloides infection in refugees. Can J Infect Dis Med Microbiol. 2013;24(2):93-6.

16. Mejia R, Nutman TB. Screening, prevention, and treatment for hyperinfection syndrome and disseminated infections caused by Strongyloides stercoralis. Curr Opin Infect Dis. 2012;25(4):45863. This study provides recommendations for the screening and management of severe strongyloidiasis.

17. Dawson-Hahn EE, Greenberg SL, Domachowske JB, Olson BG. Eosinophilia and the seroprevalence of schistosomiasis and strongyloidiasis in newly arrived pediatric refugees: an examination of 
Centers for Disease Control and Prevention screening guidelines. J Pediatr. 2010;156(6):1016-8. 8 el.

18. Siddiqui AA, Berk SL. Diagnosis of Strongyloides stercoralis infection. Clin Infect Dis. 2001;33(7):1040-7.

19. Sato Y, Kobayashi J, Toma H, Shiroma Y. Efficacy of stool examination for detection of Strongyloides infection. Am J Trop Med Hyg. 1995;53(3):248-50.

20. Uparanukraw P, Phongsri S, Morakote N. Fluctuations of larval excretion in Strongyloides stercoralis infection. Am J Trop Med Hyg. 1999;60(6):967-73.

21. Katz N, Chaves A, Pellegrino J. A simple device for quantitative stool thick-smear technique in Schistosomiasis mansoni. Rev Inst Med Trop Sao Paulo. 1972;14(6):397-400.

22. Steinmann P, Zhou XN, Du ZW, Jiang JY, Wang LB, Wang XZ, et al. Occurrence of Strongyloides stercoralis in Yunnan Province, China, and comparison of diagnostic methods. PLoS Negl Trop Dis. 2007;1(1):e75.

23. Knopp S, Mgeni AF, Khamis IS, Steinmann P, Stothard JR, Rollinson D, et al. Diagnosis of soil-transmitted helminths in the era of preventive chemotherapy: effect of multiple stool sampling and use of different diagnostic techniques. PLoS Negl Trop Dis. 2008;2(11):e331.

24. Bundy DA, Hall A, Medley GF, Savioli L. Evaluating measures to control intestinal parasitic infections. World Health Stat Q. 1992;45(2-3):168-79.

25. Glinz D, Silue KD, Knopp S, Lohourignon LK, Yao KP, Steinmann $\mathrm{P}$, et al. Comparing diagnostic accuracy of Kato-Katz, Koga agar plate, ether-concentration, and FLOTAC for Schistosoma mansoni and soil-transmitted helminths. PLoS Negl Trop Dis. 2010;4(7): e754.

26. Repetto SA, Duran PA, Lasala MB, Gonzalez-Cappa SM. High rate of strongyloidosis infection, out of endemic area, in patients with eosinophilia and without risk of exogenous reinfections. Am J Trop Med Hyg. 2010;82(6):1088-93.

27. Intapan PM, Maleewong W, Wongsaroj T, Singthong S, Morakote N. Comparison of the quantitative formalin ethyl acetate concentration technique and agar plate culture for diagnosis of human strongyloidiasis. J Clin Microbiol. 2005;43(4):1932-3.

28. Baermann. Eine einfache Methode zur Auffindung von Ankylostomum -(Nematoden)- Larven in Erdproben. Welteureden. Batavia: Genesk. Lab. Feestbundel; 1917. p. 41-7.

29. Zaha O, Hirata T, Kinjo F, Saito A. Strongyloidiasis: progress in diagnosis and treatment. Intern Med. 2000;39(9):695-700.

30. de Kaminsky RG. Evaluation of three methods for laboratory diagnosis of Strongyloides stercoralis infection. J Parasitol. 1993;79(2):277-80.

31. Jongwutiwes S, Charoenkorn M, Sitthichareonchai P. Akaraborvorn P, Putaporntip C. Increased sensitivity of routine laboratory detection of Strongyloides stercoralis and hookworm by agar-plate culture. Trans R Soc Trop Med Hyg. 1999;93(4): 398-400.

32. Ines ED, Souza JN, Santos RC, Souza ES, Santos FL, Silva ML, et al. Efficacy of parasitological methods for the diagnosis of Strongyloides stercoralis and hookworm in faecal specimens. Acta Trop. 2011 Aug 27. This study compares different parasitologic methods outlining that increasing the sensitivity of the detection requires the use of different parasitologic methods, including $A P C$.

33. Nielsen PB, Mojon M. Improved diagnosis of strongyloides stercoralis by seven consecutive stool specimens. Zentralbl Bakteriol Mikrobiol Hyg A. 1987;263(4):616-8.

34. Hirata T, Nakamura H, Kinjo N, Hokama A, Kinjo F, Yamane N, et al. Increased detection rate of Strongyloides stercoralis by repeated stool examinations using the agar plate culture method. Am J Trop Med Hyg. 2007;77(4):683-4.

35. Koosha S, Fesharaki M, Rokni MB. Comparison of enzyme-linked immunosorbent assay and indirect immunofluorescence assay in the diagnosis of human strongyloidiasis. Indian $\mathrm{J}$ Gastroenterol. 2004;23(6):214-6.

36. Gam AA, Neva FA, Krotoski WA. Comparative sensitivity and specificity of ELISA and IHA for serodiagnosis of strongyloidiasis with larval antigens. Am J Trop Med Hyg. 1987;37(1):157-61.

37. Yori PP, Kosek M, Gilman RH, Cordova J, Bern C, Chavez CB, et al. Seroepidemiology of strongyloidiasis in the Peruvian Amazon. Am J Trop Med Hyg. 2006;74(1):97-102.

38. Sudarshi S, Stumpfle R, Armstrong M, Ellman T, Parton S, Krishnan P, et al. Clinical presentation and diagnostic sensitivity of laboratory tests for Strongyloides stercoralis in travellers compared with immigrants in a non-endemic country. Trop Med Int Health. 2003;8(8):728-32.

39. Schaffel R, Nucci M, Carvalho E, Braga M, Almeida L, Portugal R, et al. The value of an immunoenzymatic test (enzyme-linked immunosorbent assay) for the diagnosis of strongyloidiasis in patients immunosuppressed by hematologic malignancies. Am J Trop Med Hyg. 2001;65(4):346-50.

40. Huaman MC, Sato Y, Aguilar JL, Terashima A, Guerra H, Gotuzzo E, et al. Gelatin particle indirect agglutination and enzyme-linked immunosorbent assay for diagnosis of strongyloidiasis using Strongyloides venezuelensis antigen. Trans R Soc Trop Med Hyg. 2003;97(5):535-8.

41. Abdul-Fattah MM, Nasr ME, Yousef SM, Ibraheem MI, AbdulWahhab SE, Soliman HM. Efficacy of ELISA in diagnosis of strongyloidiasis among the immune-compromised patients. J Egypt Soc Parasitol. 1995;25(2):491-8.

42. Boscolo M, Gobbo M, Mantovani W, Degani M, Anselmi M, et al. Evaluation of an indirect immunofluorescence assay for strongyloidiasis as a tool for diagnosis and follow-up. Clin Vaccine Immunol. 2007;14:129-33.

43. Silva LP, Barcelos IS, Passos-Lima AB, Espindola FS, Campos $\mathrm{DM}$, et al. Western blotting using Strongyloides ratti antigen for the detection of IgG antibodies as confirmatory test in human strongyloidiasis. Mem Inst Oswaldo Cruz. 2003;98:687-91.

44. Lindo JF, Conway DJ, Atkins NS, Bianco AE, Robinson RD, et al. Prospective evaluation of enzyme-linked immunosorbent assay and immunoblot methods for the diagnosis of endemic Strongyloides stercoralis infection. Am J Trop Med Hyg. 1994;51:175-9.

45. van Doorn HR, Koelewijn R, Hofwegen H, Gilis H, Wetsteyn JC, Wismans PJ, et al. Use of enzyme-linked immunosorbent assay and dipstick assay for detection of Strongyloides stercoralis infection in humans. J Clin Microbiol. 2007;45(2):438-42.

46. Loutfy MR, Wilson M, Keystone JS, Kain KC. Serology and eosinophil count in the diagnosis and management of strongyloidiasis in a non-endemic area. Am J Trop Med Hyg. 2002;66(6):749-52.

47. Neva FA, Gam AA, Burke J. Comparison of larval antigens in an enzyme-linked immunosorbent assay for strongyloidiasis in humans. J Infect Dis. 1981;144(5):427-32.

48. Genta RM. Predictive value of an enzyme-linked immunosorbent assay (ELISA) for the serodiagnosis of strongyloidiasis. Am J Clin Pathol. 1988;89(3):391-4.

49. Bailey JW. A serological test for the diagnosis of Strongyloides antibodies in ex far East prisoners of war. Ann Trop Med Parasitol. 1989;83(3):241-7.

50. Carroll SM, Karthigasu KT, Grove DI. Serodiagnosis of human strongyloidiasis by an enzyme-linked immunosorbent assay. Trans R Soc Trop Med Hyg. 1981;75(5):706-9.

51. Machado ER, Ueta MT, de Fatima Goncalves-Pires Mdo R, de Oliveira JB A, Faccioli LH, Costa-Cruz JM. Strongyloides venezuelensis alkaline extract for the diagnosis of human strongyloidiasis by enzyme-linked immunosorbent assay. Mem Inst Oswaldo Cruz. 2003;98(6):849-51.

52. Ravi V, Ramachandran S, Thompson RW, Andersen JF, Neva FA. Characterization of a recombinant immunodiagnostic antigen (NIE) 
from Strongyloides stercoralis L3-stage larvae. Mol Biochem Parasitol. 2002;125(1-2):73-81.

53. Krolewiecki AJ, Ramanathan R, Fink V, McAuliffe I, Cajal SP, Won $\mathrm{K}$, et al. Improved diagnosis of Strongyloides stercoralis using recombinant antigen-based serologies in a community-wide study in northern Argentina. Clin Vaccine Immunol. 2010;17(10):1624-30.

54. Ramanathan R, Burbelo PD, Groot S, Iadarola MJ, Neva FA, Nutman TB. A luciferase immunoprecipitation systems assay enhances the sensitivity and specificity of diagnosis of Strongyloides stercoralis infection. J Infect Dis. 2008;198(3):444-51.

55.• Bisoffi Z, Buonfrate D, Sequi M, Mejia R, Cimino RO, Krolewiecki AJ, et al. Diagnostic accuracy of five serologic tests for Strongyloides stercoralis infection. PLoS Negl Trop Dis. 2014;8(1):e2640. This recent study compares five different serologic techniques and argues the utility of each method.

56. Sykes AM, McCarthy JS. A coproantigen diagnostic test for Strongyloides infection. PLoS Negl Trop Dis. 2011;5(2):e955. This novel technique based on feces-antigen detection has shown promising results although it still need to be tested and validated in clinical practice.

57. El-Badry AA. ELISA-based coproantigen in human strongyloidiaisis: a diagnostic method correlating with worm burden. J Egypt Soc Parasitol. 2009;39(3):757-68.

58. Moghaddassani H, Mirhendi H, Hosseini M, Rokni M, Mowlavi G, Kia E. Molecular diagnosis of Strongyloides stercoralis infection by PCR detection of specific DNA in human stool samples. Iran J Parasitol. 2011;6(2):23-30.

59. Ahmad AF, Hadip F, Ngui R, Lim YA, Mahmud R. Serological and molecular detection of Strongyloides stercoralis infection among an Orang Asli community in Malaysia. Parasitol Res. 2013;112(8): 2811-6.

60. Keiser J, Thiemann K, Endriss Y, Utzinger J. Strongyloides ratti: in vitro and in vivo activity of tribendimidine. PLoS Negl Trop Dis. 2008;2(1):e136.

61. Kramme S, Nissen N, Soblik H, Erttmann K, Tannich E, Fleischer $\mathrm{B}$, et al. Novel real-time PCR for the universal detection of Strongyloides species. J Med Microbiol. 2011;60(Pt 4):454-8.

62.• Knopp S, Salim N, Schindler T, Karagiannis Voules DA, Rothen J, Lweno O, et al. Diagnostic accuracy of Kato-Katz, FLOTAC, Baermann, and PCR methods for the detection of light-intensity hookworm and Strongyloides stercoralis infections in Tanzania. Am J Trop Med Hyg. 2014;90(3):535-45. This study compares different parasitologic methods with the PCR technique, and shows that all techniques failed to detect very low-intensity infections.

63. Verweij JJ, Canales M, Polman K, Ziem J, Brienen EA, Polderman AM, et al. Molecular diagnosis of Strongyloides stercoralis in faecal samples using real-time PCR. Trans R Soc Trop Med Hyg. 2009;103(4):342-6.

64. Schar F, Odermatt P, Khieu V, Panning M, Duong S, Muth S, et al. Evaluation of real-time PCR for Strongyloides stercoralis and hookworm as diagnostic tool in asymptomatic schoolchildren in Cambodia. Acta Trop. 2013;126(2):89-92. This study shows that PCR techniques are less sensitive in asymptomatic patients compared with symptomatic patients.

65. Sultana Y, Jeoffreys N, Watts MR, Gilbert GL, Lee R. Real-time polymerase chain reaction for detection of Strongyloides stercoralis in stool. Am J Trop Med Hyg. 2013;88(6):1048-51.

66. Marcos LA, Terashima A, Dupont HL, Gotuzzo E. Strongyloides hyperinfection syndrome: an emerging global infectious disease. Trans R Soc Trop Med Hyg. 2008;102(4):314-8.

67. Notomi T, Okayama H, Masubuchi H, Yonekawa T, Watanabe K, Amino N, et al. Loop-mediated isothermal amplification of DNA. Nucleic Acids Res. 2000;28(12):E63.
68. Adams ER, Schoone GJ, Ageed AF, Safi SE, Schallig HD. Development of a reverse transcriptase loop-mediated isothermal amplification (LAMP) assay for the sensitive detection of Leishmania parasites in clinical samples. Am J Trop Med Hyg. 2010;82(4):591-6.

69. Li X, Liu W, Wang J, Zou D, Wang X, Yang Z, et al. Rapid detection of Trichinella spiralis larvae in muscles by loopmediated isothermal amplification. Int J Parasitol. 2012;42(1314):1119-26.

70. Poole CB, Tanner NA, Zhang Y, Evans Jr TC, Carlow CK Diagnosis of brugian filariasis by loop-mediated isothermal amplification. PLoS Negl Trop Dis. 2012;6(12):e1948.

71. Abdul-Ghani R, Al-Mekhlafi AM, Karanis P. Loop-mediated isothermal amplification (LAMP) for malarial parasites of humans: would it come to clinical reality as a point-of-care test? Acta Trop. 2012;122(3):233-40.

72. Nkouawa A, Sako Y, Li T, Chen X, Nakao M, Yanagida T, et al. A loop-mediated isothermal amplification method for a differential identification of Taenia tapeworms from human: application to a field survey. Parasitol Int. 2012;61(4):723-5.

73. Watts MR, James G, Sultana Y, Ginn AN, Outhred AC, Kong $\mathrm{F}$, et al. A loop-mediated isothermal amplification (LAMP) assay for Strongyloides stercoralis in stool that uses a visual detection method with SYTO-82 fluorescent dye. Am J Trop Med Hyg. 2014;90(2):306-11. This study is the first assay with LAMP to detect $S$. stercoralis although it needs to be validated in clinical practice.

74. Dreyer G, Fernandes-Silva E, Alves S, Rocha A, Albuquerque R, Addiss D. Patterns of detection of Strongyloides stercoralis in stool specimens: implications for diagnosis and clinical trials. J Clin Microbiol. 1996;34(10):2569-71.

75. Schar F, Hattendorf J, Khieu V, Muth S, Char MC, Marti HP, et al. Strongyloides stercoralis larvae excretion patterns before and after treatment. Parasitology. 2014;141(7):892-7.

76. Lindo JF, Atkins NS, Lee MG, Robinson RD, Bundy DA. Parasitespecific serum $\operatorname{IgG}$ following successful treatment of endemic strongyloidiasis using ivermectin. Trans R Soc Trop Med Hyg. 1996;90(6):702-3.

77. Satoh M, Kokaze A. Treatment strategies in controlling strongyloidiasis. Expert Opin Pharmacother. 2004;5(11):2293-301.

78. Page WA, Dempsey K, McCarthy JS. Utility of serological follow-up of chronic strongyloidiasis after anthelminthic chemotherapy. Trans R Soc Trop Med Hyg. 2006;100(11): 1056-62.

79. Karunajeewa H, Kelly H, Leslie D, Leydon J, Saykao P, Biggs BA. Parasite-specific IgG response and peripheral blood eosinophil count following albendazole treatment for presumed chronic strongyloidiasis. J Travel Med. 2006;13(2):84-91.

80. Biggs BA, Caruana S, Mihrshahi S, Jolley D, Leydon J, Chea L, et al. Management of chronic strongyloidiasis in immigrants and refugees: is serologic testing useful? Am J Trop Med Hyg. 2009;80(5):788-91.

81. Salvador F, Sulleiro E, Sanchez-Montalva A, Saugar JM, Rodriguez E, Pahissa A, et al. Usefulness of Strongyloides stercoralis serology in the management of patients with eosinophilia. Am J Trop Med Hyg. 2014;90(5):830-4.

82. Segarra-Newnham M. Manifestations, diagnosis, and treatment of Strongyloides stercoralis infection. Ann Pharmacother. 2007;41(12):1992-2001.

83. Bisoffi Z, Buonfrate D, Angheben A, Boscolo M, Anselmi M, Marocco S, et al. Randomized clinical trial on ivermectin versus thiabendazole for the treatment of strongyloidiasis. PLoS Negl Trop Dis. 2011;5(7):e1254. 